\title{
Colonic manometry in children with chronic intestinal pseudo-obstruction
}

\author{
C Di Lorenzo, A F Flores, S N Reddy, W J Snape Jr, G Bazzocchi, P E Hyman
}

\begin{abstract}
Pressure changes were evaluated in the transverse, descending, and rectosigmoid colon of 30 children with chronic intestinal pseudoobstruction. Twenty two had severe lifelong constipation and eight had symptoms suggesting a motility disorder exclusively of the upper gastrointestinal tract. Based on prior antroduodenal manometry, 24 children were diagnosed as having a neuropathic and six a myopathic form of intestinal pseudoobstruction. On the day of study, endoscopy was used to place a manometry catheter into the transverse colon and intraluminal pressure was recorded for more than four hours. After a baseline recording, we gave a meal to assess the gastrocolonic response. Colonic contractions were noted in 24 children. The six children with no colonic contractions had a hollow visceral myopathy and constipation. In the children with colonic contractions, fasting motility did not differentiate children with and without constipation. After the meal, in all eight children without constipation there was (1) an increase in motility index (3.2 (SEM 0.3) $\mathrm{mm} \mathrm{Hg} / \mathrm{min}$ basal $v$ 8.4 (SEM 1.1) $\mathrm{mm} \mathrm{Hg} / \mathrm{min}$ postprandial; $p<0.001$ ), and (2) at least one high amplitude propagated contraction (HAPC). In the 16 constipated children with colonic contractions the motility index did not significantly increase after the meal (2.1 (SEM 0.3 ) $\mathrm{mm} \mathrm{Hg} / \mathrm{min}$ basal $v$ 3.1 (SEM 0.4) $\mathrm{mm} \mathrm{Hg}$ / min postprandial) and 12 of them had no HAPCs $(p<0.01 v$ group without constipation). In summary, in children with a clinical diagnosis of chronic intestinal pseudoobstruction, constipation is associated with absence of HAPCs, and the gastrocolonic response or with total absence of colonic contractions. It is concluded that studies of colonic manometry are feasible in children and may document discrete abnormalities in those with intestinal pseudo-obstruction with colonic involvement.

(Gut 1993; 34: 803-807)
\end{abstract}

Chronic intestinal pseudo-obstruction (CIP) is a heterogeneous group of disorders that vary in cause, severity, course, and response to treatment. Pathophysiology of the various subtypes of CIP is only now being elucidated. There is a wide range of abnormalities of gastric, small intestinal, and colonic myoelectric activity and contractions, and in nerve and muscle histopathology.' To diagnose and intervene appropriately it is often necessary to be able to evaluate the complete gastrointestinal tract. Oesophageal, anorectal, and antroduodenal manometry are diagnostic tools in many paediatric centres, but little is known about colonic manometry. Previous study of colonic pressures in paediatric patients has been limited mainly to the rectosigmoid area, ${ }^{2}$ because of relative inaccessibility of the proximal colon. Information concerning motility of the entire colon has been obtained by indirect measures such as the movement of radioopaque markers ${ }^{3}$ or barium ${ }^{4}$ to assess colonic transit time. Newer techniques provide more specific and often complementary information about colon transit and motor activity. Manometry, ${ }^{5}$ electromyography, ${ }^{6}$ and scintiscanning $^{7-10}$ have been used in adults in the investigation of colon motility but only recently have these been extended to the study of paediatric patients. ${ }^{11}$

The aim of our study was to clarify the pathophysiology of constipation in children with CIP and to correlate abnormal motility patterns with distinctive clinical presentations or pathology.

\section{Methods}

Before each study informed consent was obtained from a parent, and assent was obtained from any subject seven years of age or older.

\section{SUBJECTS}

Thirty children, $1 \cdot 1$ to $11 \cdot 6$ years of age (mean age $4 \cdot 1$ years, 18 female), were referred by paediatric gastroenterologists for evaluation of severe symptoms unresponsive to conventional management (Table I). Duration of symptoms was at least one year in every patient (mean 3.7 years). All the patients carried a diagnosis of chronic intestinal pseudo-obstruction based on recurrent symptoms of bowel obstruction without physical lesion. ${ }^{12}$ Before colon manometry, all underwent antroduodenal manometry to discriminate between disorders of myopathic or neuropathic origin. ${ }^{1314}$ Nine patients had a diagnosis based on a small bowel full thickness biopsy (Table II). From these studies, it was established that 24 children had a neuropathy (mean age 4.4 years) and six a myopathy (mean age 3.2 years). Eight of the children with neuropathy did not have constipation, diarrhoea, or any other symptoms of colonic disease (mean age 4.5 years)

\section{STUDY DESIGN AND INSTRUMENTATION}

We prescribed a clear liquid diet for all children during the 48 hours before study. On the day before study, the patients underwent a preparation for colonoscopy, designed for each patient on the basis of the patient's age, symptoms, and ability to tolerate lavage solutions. We infused a 
TABLE I Symptoms and the means of alimentation in patients with and without constipation

\begin{tabular}{lll}
\hline & $\begin{array}{l}\text { Constipation } \\
(n=22)\end{array}$ & $\begin{array}{l}\text { Non- } \\
\text { constipation } \\
(n=8)\end{array}$ \\
\hline Less than one bowel movement a & & \\
$\quad$ week & 22 & 0 \\
Abdominal pain & 20 & 4 \\
Nausea and vomiting & 20 & 8 \\
Chronic abdominal distension & 18 & 6 \\
Recurrent urinary tract infections & 8 & 0 \\
Tube feeding & 4 & 4 \\
Parenteral nutrition & 9 & 3 \\
\hline
\end{tabular}

balanced electrolyte solution (Colyte, Reed, and Carnick, Piscataway, NJ) through a pre-existing gastrostomy or through a nasogastric tube in those able to tolerate enteral feedings. We used enemas when it was not possible to utilise the enteral lavage. No additional colonic preparation was used on the morning of the study, and the patients fasted for at least five hours before colonoscopy.

On the day of the study a colonoscopy was performed with minimal air insufflation and minimal sedation (midazolam $(0.05 \mathrm{mg} / \mathrm{kg}$ ) intravenously). After reaching the midtransverse colon, a soft tipped teflon biliary guidewire (length $480 \mathrm{~cm}$, diameter $0.052 \mathrm{~cm}$; Wilson-Cook, Wilson-Salem, NC) was inserted through the colonoscope. The guidewire was positioned in the transverse or ascending colon and the colonoscope was withdrawn, leaving the guidewire in position. A seven lumen manometric catheter, with recording orifices radially oriented and spaced $15 \mathrm{~cm}$ apart (Arndorfer Medical Specialities, Greendale, Wis), was then advanced over the guidewire. The guidewire was removed and the catheter taped to the patient's thigh.

The subjects were placed supine under a gamma camera and we waited at least one hour to allow the patients to recover from the procedure. The position of the manometric catheter was confirmed on the persistence oscilloscope of the gamma camera by introducing into the catheter, via the proximal recording orifice, $2 \mathrm{ml}$ of $0.9 \%$ $\mathrm{NaCl}$ solution containing $4 \mathrm{MBq}(0.1 \mathrm{mCi})$ of ${ }^{99} \mathrm{~m}$ Tc DTPA. This marker remained in the catheter until it was removed by aspiration after confirmation that the recording sites were in the distal half of the transverse colon, the splenic flexure, the descending colon, the sigmoid colon, and the rectum. The catheters were continuously perfused at $0.1 \mathrm{ml} / \mathrm{min}$ with distilled water by a

TABLE II Pathology and antroduodenal motility findings in all the patients studied

\begin{tabular}{lc}
\hline & $\begin{array}{c}\text { Noof } \\
\text { children }\end{array}$ \\
\hline $\begin{array}{l}\text { Pathology }(n=9): \\
\text { Myopathy (hollow visceral myopathy }\end{array}$ & 4 \\
$\begin{array}{c}\text { Neuropathy (absence or immaturity of myenteric } \\
\text { plexus) }\end{array}$ & 5 \\
$\begin{array}{c}\text { Antroduodenal motility }(\mathrm{n}=30) \text { : } \\
\text { Myopathy (coordinated contractions of low } \\
\text { amplitude) }\end{array}$ & 6 \\
$\begin{array}{c}\text { Neuropathy (absence of migrating motor complex, } \\
\text { uncoordinated contractions of normal amplitude) }\end{array}$ & 24 \\
\hline
\end{tabular}

low compliance capillary system (Arndorfer Medical Specialties). ${ }^{15}$ Pressure was transmitted to transducers (Statham P231A, Statham Instruments, Oxnard, CA) and recorded on a rectilinear recorder (Beckman R611, Beckman Instruments Inc, Fullerton, CA) and on a personal computer system.

After at least 120 minutes of fasting recording, the patients were fed. The complex liquid meal was designed for each patient on the basis of age and current mode of nutritional support. In those enterally fed $(n=18)$ we gave $240 \mathrm{ml}$ of whole milk or infant formula. In those on parenteral nutrition $(n=12)$ we gave the maximum amount of milk the patients were able to ingest without symptoms, and at the end of the test we emptied the gastric content via their gastrostomies. The minimum volume given to each patient was $90 \mathrm{ml}$. The two groups of constipated and non-constipated children received a similar amount of milk $(190(10) \mathrm{ml} v$ 210 (13) ml respectively). Each subject's upper body was tilted slightly to provide comfortable drinking. Each subject was asked to consume the meal in less than 10 minutes. We recorded motility for at least 90 minutes after the meal.

\section{STUDY EVALUATION}

\section{Motor activity}

A colonic motility index was calculated with a computerised program, by measuring the area under the pressure records for the 60 minute period immediately preceding and the 60 minute period immediately after completion of the meal. The motility index was expressed as $\mathrm{mm} \mathrm{Hg}$ / min. The motility indices obtained from the different recording sites were averaged to obtain only one basal and one postprandial motility index for each patient. Only contractions greater than $5 \mathrm{~mm} \mathrm{Hg}$ were included in the analysis.

Patterns of colonic motor contractions were identified visually. Movement artefacts gave rapid fluctuations that occurred simultaneously at all recording sites and were easily differentiated from colonic contractions and discarded from analysis. Non-propagating contractions were defined as contractions that did not propagate at least $15 \mathrm{~cm}$ between the recording ports. Propagating contractions were those that appeared at adjacent recording sites within 30 seconds of each other. These were defined as antegrade or retrograde based on their aborad or orad propagation respectively. High amplitude propagated contractions (HAPCs) were defined as contractions with amplitude of at least $100 \mathrm{~mm} \mathrm{Hg}$ in at least two recording sites, propagating for at least $30 \mathrm{~cm}$ (over three or more recording sites).

\section{Statistical analysis}

The Wilcoxon signed rank test was used to compare the differences between motility index during the baseline period and postprandial period. $\mathrm{A} \chi^{2}$ test was used to compare percentage of children with and without HAPCs in the different groups of patients. Results are expressed as mean (SEM). 
TABLE III Summary of quantitative results

\begin{tabular}{llll}
\hline & $\begin{array}{l}\text { Non- } \\
\text { constipation }\end{array}$ & Neuropathy & Myopathy \\
\hline No of patients: & 8 & 16 & 6 \\
With fasting HAPCs & 3 & 0 & 0 \\
With postprandial HAPC & $8^{\star}$ & 4 & 0 \\
With retrograde contractions & 1 & 4 & 0 \\
Fasting motility index (MI) & $3 \cdot 2(0 \cdot 3)$ & $2 \cdot 1(0 \cdot 3)$ & 0 \\
Postprandial MI & $8 \cdot 4(1 \cdot 1)^{\star \star}$ & $3 \cdot 1(0 \cdot 4)$ & 0 \\
Patients with 2 fold increase in MI & $8^{\star \star}$ & 2 & 0 \\
\hline
\end{tabular}

${ }^{\star} \mathrm{p}<0.01$ non-constipation $v$ neuropathy and myopathy; ${ }^{\star \star} \mathrm{p}<0.001 v$ fasting MI. Motility index expressed as mean (SEM) $\mathrm{mm} \mathrm{Hg} / \mathrm{min}$.

\section{Results}

Table III summarises the results. Twenty two patients had colonic contractions during fasting and after the meal. Two children had contractions only after feeding. In six subjects there were no contractions during the entire study. Sixteen children had both propagated and non-propagated contractions, one had only propagated contractions and the other seven only non-propagated contractions. Retrograde contractions were recorded in four constipated and in one non-constipated patient. HAPCs (Fig 1) constituted $57 \%$ of the propagated contractions. When HAPCs were excluded from the propagated contractions there was no difference in the percentage of propagated and non-propagated contractions in the group of patients with and without constipation. In $65 \%$ of episodes, HAPCs were associated with the passage of flatus, or stool, or both. In most cases, HAPCs began from the most proximal recording site and migrated to the sigmoid region. Only $21 \%$ of HAPCs propagated to the rectum. Mean speed of propagation of the HAPCs was $0.9(0.3) \mathrm{cm} / \mathrm{s}$ (range $0.5-2 \cdot 2 \mathrm{~cm} / \mathrm{s}$ ).

All eight children in the non-constipated group had contractions in both fasting and fed states. The postprandial colonic motility index increased significantly, when compared with basal values, in this group of chilui $n$ ( $3 \cdot 2(0 \cdot 3)$ $\mathrm{mm} \mathrm{Hg} / \mathrm{min}$ basal $v 8.4(1 \cdot 1) \mathrm{mm} \mathrm{Hg} / \mathrm{min}$ post-

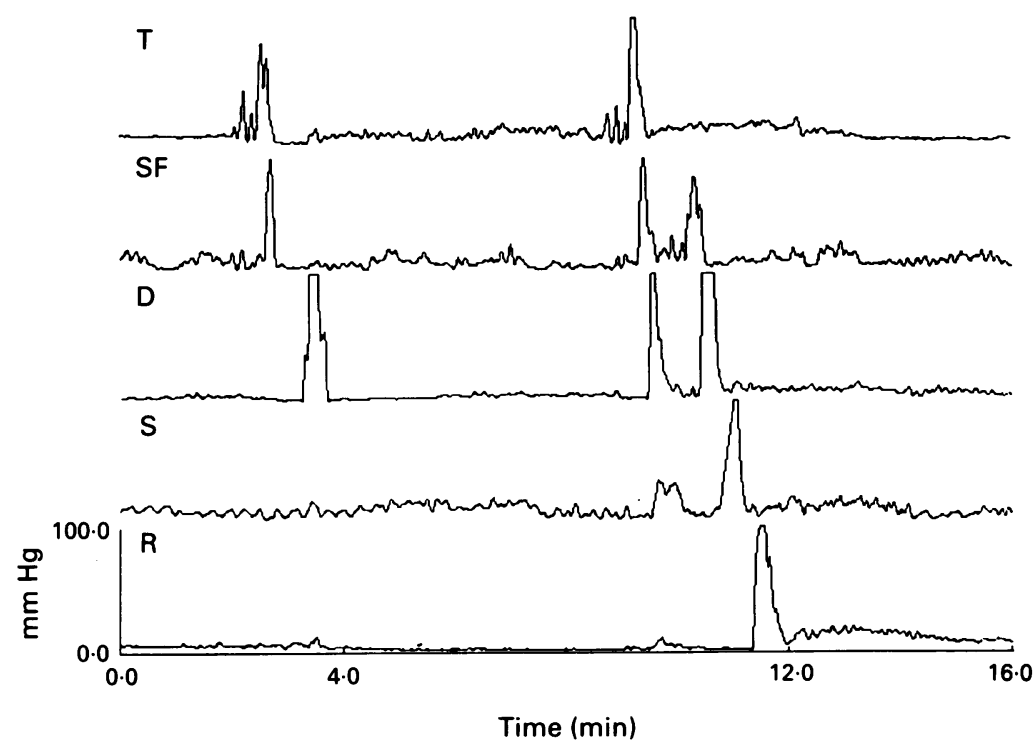

Figure 1: Three high amplitude propagated contractions (HAPCs) after the meal in a child without constipation. Pressures are recorded in the transverse colon $(T)$, splenic flexure $(S F)$, descending colon $(D)$, sigmoid $(S)$, and rectum $(R)$.

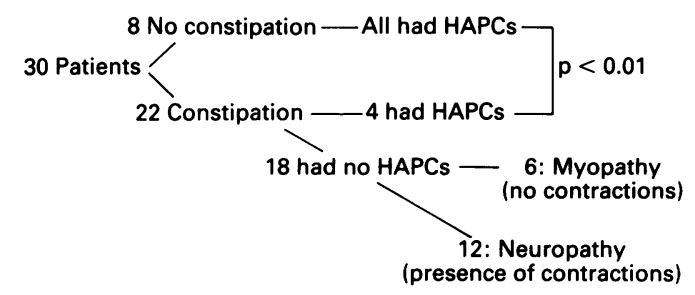

Figure 2: Presence of HAPCs is uncommon in patients with constipation. In patients without $H A P C s$, the complete absence of contractions allows discrimination of patients with myopathy from those with neuropathy. Abbreviations as for Figure1.

prandial, $\mathrm{p}<0.001)$. There was no correlation between volume or caloric content of the meal (analysed as $\mathrm{ml} / \mathrm{kg}$ and $\mathrm{Kcal} / \mathrm{kg}$ ) given to the patient and the increase of his postprandial motility index. All non-constipated subjects had HAPCs within 30 minutes after beginning the meal. They averaged 3.6 HAPCs during the first 60 minutes after the meal (range 1-12). Three of eight subjects also had HAPCs during fasting.

Postprandial HAPCs were found only in four of 16 subjects with neuropathic disorders, a significant decrease compared with the nonconstipated group ( $p<0.01$ ) (Fig 2). No patient with neuropathy had HAPCs during fasting. There was no difference in the speed of HAPCs between patients with neuropathy and nonconstipated patients. The presence of HAPCs had a $67 \%$ predictive value for not having constipation and the absence of HAPCs had a $100 \%$ predictive value for having constipation. There were no manometric features in the fasting motility that differentiated the patients without constipation from those with neuropathy and constipation. By contrast with the nonconstipated subjects, the patients with neuropathic constipation had no significant increase in their postprandial motility index $(2 \cdot 1(0 \cdot 3) \mathrm{mm}$ $\mathrm{Hg} / \mathrm{min}$ basal $v 3.1(0.4) \mathrm{mm} \mathrm{Hg} / \mathrm{min}$ postprandial, NS). A twofold increase in motility index after the meal was present in two patients with neuropathy and in all non-constipated patients $(2 / 16 v 8 / 8, \mathrm{p}<0.001)$. Although four patients with neuropathy and constipation had HAPCs and two had a twofold increase in motility index after the meal, no patient with neuropathy had both these features.

The six children with myopathy had no contractions at any time. Therefore their motility index was zero before and after the meal. The absence of contractions throughout the entire study distinguished subjects with myopathy from the non-constipated group and from the patients with neuropathy.

Two patients in the non-constipated group had, during fasting, a rectal motor complex (RMC), ${ }^{16}$ a cluster of contractions at a rate of $7-9 / \mathrm{min}$ found only in the rectum (Fig 3).

There were no adverse events during the studies.

\section{Discussion}

In this study we investigated colonic motility in children with chronic intestinal pseudoobstruction. We divided the study population into two groups: subjects with symptoms sug- 


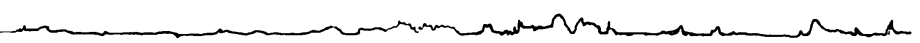

Transverse colon

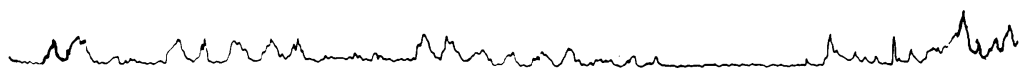

Descending colon

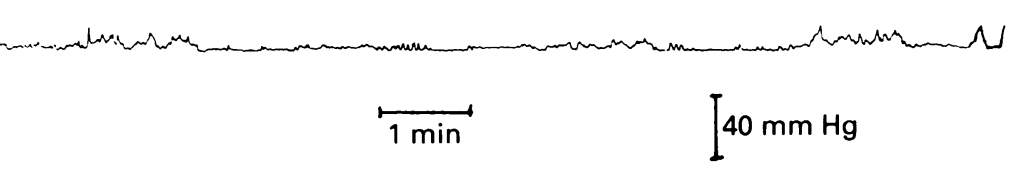

Sigmoid colon

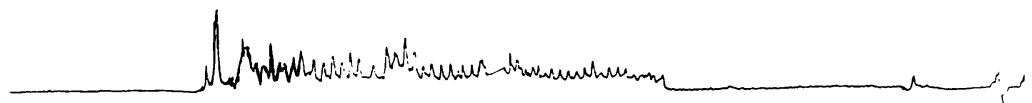

Rectum

Figure 3: Colon manometry from a child without constipation. There are non-propagating contractions in the transverse colon and a rectal motor complex in the rectum that lasts six minutes and has a frequency of contractions of $7 \cdot 2 / \mathrm{min}$.

gestive of involvement of the entire gastrointestinal tract, and subjects with disease limited to the stomach and small intestine. All the children had physiology of their upper tract involvement clarified by antroduodenal motility studies and in some cases by full thickness surgical biopsies. Both methods differentiate myopathic from neuropathic pseudoobstruction. ${ }^{1}$ We assumed no colonic involvement in the patients without constipation. Although this group of non-constipated patients does not constitute a truly normal population, a history of regular bowel movements, an increase in the motility index after a meal, and the presence of HAPCs suggest normal colon motility. These same characteristics were found in children with functional faecal retention, a condition common in the school age child, ${ }^{11}$ in which physiology of the colon is believed to be normal and constipation results from retentive behaviour by a child who is afraid of painful defecation.

In CIP oesophageal manometry is abnormal in more than $50 \%$ of children, ${ }^{17}$ antroduodenal manometry is abnormal in virtually all, ${ }^{18}$ but anorectal manometry is normal. Thus until this study there was no clear explanation for constipation in CIP. Finding what we believe to be normal colon motility in children without constipation and abnormal upper gastrointestinal motility suggests that in some children CIP does not involve the colon.

We used a standardised manometric technique for measurement of luminal pressures. This technique has been utilised successfully in adults to elucidate the pathophysiology of constipation, ${ }^{19}$ diarrhoea, ${ }^{20}$ and as a clinical test to determine the severity of colonic motility disorder in symptomatic patients. The absence of a repetitive, frequent, easily recognisable motor pattern in the colon may be one of the reasons for the lack of data on colon motor activity in paediatric patients. The interdigestive cycle of motor activity, or migrating motor complex, starts from the lower oesophagus and migrates but ends in the terminal ileum. ${ }^{21}$ Recently, a rectal motor complex that is not synchronous with or related to the migrating motor complex was reported. ${ }^{16}$ We found rectal motor complexes in two children.

We chose to place the manometric catheter into the transverse colon. As the splenic flexure is an anatomical region easily reached and identified by an experienced endoscopist, we found easy access to this region and then advanced either the endoscope or the guidewire into the transverse colon. In this way all the procedures were short in duration and were performed with minimal sedation. Because there is little motor activity in the healthy colon during sleep, sedation was minimised and we waited until the patient was awake before starting the testing. After the catheter placement, we used a radioactive marker to delineate the catheter position and recording sites.

Eating is an important stimulus for colonic motility in healthy human subjects. ${ }^{5}$ Healthy adults exhibit an increase in colon motility beginning 20 to 40 minutes after a meal, known as the gastrocolonic response..$^{22}$ In this study, most of the patients with severe constipation failed to increase their motility index after eating. In adults the gastrocolonic response is absent in the early stages of progressive systemic sclerosis. ${ }^{23}$ Absence of the gastrocolonic response may be an indicator for disease, as well as a contributing factor in the pathogenesis of symptoms. Although a gastrocolonic response might be documented by placing a catheter in the sigmoid colon, ${ }^{23}$ it should be noted that many HAPCs do not propagate to the distal colon and would be missed by studies of the sigmoid and rectum alone.

The presence of HAPCs was suggestive of normal colonic function; HAPCs were found after meals in all non-constipated subjects, but not in patients with myopathy or in most patients with neuropathy. The visual identification of HAPCs was easy because of their high amplitude (which did not overlap with the other contractions) and their unequivocal propagation over at least three recording sites. Often one HAPC was followed by other HAPCs at three to four minute intervals in the postprandial period. This is in accord with data previously reported in normal adults. ${ }^{24}$ We found a much higher number of HAPCs in children than previously reported in adults. ${ }^{5}$ It is possible that the highly artificial experimental condition could have played a part in increasing the number of HAPCs. The absence of normal colonic content, the water infusion through the manometry catheter, and the presence of a semirigid foreign body could have triggered more HAPCs than would be recorded in an undisturbed bowel. It is also possible that an increased number of HAPCs correlates with the increased number of bowel movements commonly found in infants and children. The HAPCs are thought to be the manometric equivalent of the mass movements seen during radiological studies although not all HAPCs are associated with mass movements. ${ }^{25}$ It is not clear what initiates HAPCs. There is some 
evidence that HAPCs can be induced by distension of the lumen ${ }^{26}$ or by luminal irritants such as olive oil and bisacodyl. ${ }^{27}$

In the evaluation of CIP in childhood, colon manometry complements the radio-opaque marker test. The last often reveals the site of functional obstruction and can differentiate among colonic inertia, hindgut dysfunction, and outlet obstruction..$^{28}$ Manometry distinguishes between myopathy, neuropathy, and normal colonic function. There were no contractions recorded from children with myopathy. We assume that contractions were totally absent or failed to occlude the intestinal lumen. It is possible that a dilated colon would generate only very low amplitude contractions that are not distinguished during manometric studies. In colonic neuropathies contractions were present, but the gastrocolonic response was absent and there were fewer HAPCs.

Scintigraphy is a less invasive approach to the study of bowel motility than manometry. It allows the study of regional transit of solids in the unprepared human colon without the need for colon intubation. ${ }^{102930}$ There are limitations to the use of scintigraphy in children with pseudoobstruction, such as the very long transit time for orally ingested capsules to reach the colon, the impossibility of peroral cannulation of the right colon, and the poor patient cooperation with lying quietly under a gamma camera. Also, scintigraphy may not differentiate clearly between neuropathy and myopathy.

In conclusion, colonic manometry is a safe and effective means to evaluate colonic motility in children with CIP. Colon manometry could be used as a diagnostic tool in selected patients to clarify the pathophysiology of severe colonic motor disorders.

The results of this study were presented in part at the Digestive Disease Week held in San Antonio, Texas, USA, May 1990.

This work was supported in part by grant MOI RR 00425 to the Harbor-UCLA Medical Center General Clinical Research Center.

1 Schuffler MD. Chronic intestinal pseudo-obstruction: progress and problems. I Pediatr Gastroenterol Nutr 1990; 10: $157-9$.

2 Davidson $\dot{M}$, Bauer $\mathrm{CH}$. Studies of colonic motility in children. Pediatrics 1958; 21: 746-51.

3 Hinton J, Lennard-Jones J, Young A. A new method of studying gut transit times using radio-opaque markers. Gut 1969; 10: 842-7.

4 Ritchie JA. Mass peristalsis in the human colon after contact with oxyphenisatin. Gut 1972; 13: 211-9.

5 Narducci F, Bassotti G, Gaburri M, Morelli A. Twenty four hour manometric recording of colonic motot activity in humans. Gut 1987; 28: 17-25.

6 Bueno L, Fioramonti J, Ruckebusch Y, Frexinos J, Coulom P. Evaluation of colon myoelectrical activity in health and functional disorders. Gut 1980; 41: 480-5.
7 Krevsky B, Malmud LS, D'Ercole F, Maurer AN, Siegel AJ Fisher RS. Colonic transit scintigraphy. A physiologic approach to the quantitative measurement of colonic transit in humans. Gastroenterology 1986; 91 : 1102-12.

8 Read NW, Al-Janabi MN, Holgate AM, Barber DC, Edwards CA. Simultaneous measurement of gastric emptying, small bowel residence and colonic filling of a solid meal by use of the gamma camera. Gut 1986; 27: 300-8.

9 Kamm MA, Lennard Jones JE, Thompson DG, Sobnack R Granowoska $M$. Dynamic scanning defines a colonic defect Granowoska M. Dynamic scanning defines a colonic defect

10 Proano M, Camilleri M, Phillips SF, Brown ML, Thomforde GM. Transit of solids through the human colon: regional quantification in the unprepared colon. Am $\mathcal{F}$ Physiol 1990 258: G856-62.

11 Di Lorenzo C, Flores AF, Reddy SN, Hyman PE. Colonic manometry to differentiate causes of intractable constipation. F Pediatr 1992; 120: 690-5

12 Hyman PE, Tomomasa T, McDiarmid SV. Intestinal pseudoobstruction in childhood. In: Milla PJ, ed. Disorders of gastrointestinal motility in childhood. New York: John Wiley, 1988: 73-80.

13 Malagelada JR, Stanghellini V. Manometric evaluation of functional upper gut symptoms. Gastroenterology 1985; 88. 1223-31

14 Hyman PE, McDiarmid SV, Napolitano J, Abrams CE Tomomasa $\mathrm{T}$. Antroduodenal motility in children with chronic intestinal pseudo-obstruction. $\mathcal{F}$ Pediatr 1988; 112 . 899-905

15 Tomomasa $T$, Itoh $Z$, Koizumi T, Kuroume T. Nonmigrating rhythmic activity in the stomach and duodenum of neonates. Biol Neonate 1985; 48: $1-9$.

16 Orkin BA, Hanson RB, Kelly KA. The rectal motor complex. Fournal of Gastrointestinal Motility 1989; 1: 5-8.

17 Byrne WJ, Cipel L, Euler AR, Halpin TC, Ament ME. Chronic idiopathic intestinal pseudo-obstruction syndrome in children - clinical characteristic and prognosis. $\mathcal{F}$ Pediatr 1977; 90: 585-9.

18 Staghellini V, Camilleri M, Malagelada JR. Chronic idiopathic intestinal pseudo-obstruction: clinical and intestinal intestinal pseudo-obstruction: 28: 5-12.

19 Bazzocchi G, Ellis J, Villanueva-Meyer J, Jing J, Reddy SN, Mena I, et al. Postprandial colonic transit and motor activity in chronic constipation. Gastroenterology 1990; 98: 686-93.

20 Chan SS, Reddy SN, Villanueva J, Mena I, Akashi K, Bazzocchi G, et al. Colonic motility and transit of intraluminal contents in ulcerative colitis. Gastroenterology 1989 96: A81.

21 Kellow JE, Borody TJ, Phillips SF, Tucker RL, Haddad AC. Human interdigestive motility: variation in patterns from

22 Wright SH, Snape WJ Jr, Battle W, Cohen S, London RL Effect of dietary components on gastrocolonic response. Am $\mathcal{F}$ Physiol 1980; 238: G228-32.

23 Battle WM, Snape WJ Jr, Wright S, Sullivan MA, Cohen S Meyers A, et al. Abnormal colonic motility in progressive Meyers A, et al. Abnormal colonic motility in prog

24 Bassotti G, Gaburri M. Manometric investigation of high amplitude propagated contractile activity of the human colon. Am f Physiol 1988; 255: G660-4

25 Lemann M, Picon L, Flourie' B, Coffin B, Rambaud JC, Rain $\mathrm{JD}$, et al. Relationship between high-amplitude propagated contractions and transit in the unprepared human colon. Gastroenterology 1992; 102: A474.

26 Narducci F, Bassotti G, Gaburri M, Solinas A, Fiorucci S, Morelli A. Distension stimulated motor activity of the human transverse, descending and sigmoid colon. Gastroenterology 1985; 88: 1515 .

27 Spiller RC, Brown ML, Phillips SF. Decreased fluid tolerance, accelerated transit and abnormal motility of the
human colon induced by oleic acid. Gastroenterology 1986; human col $100-7$.

28 Likongo Y, Devroede G, Schang JC, Arhan P, Vobecky S, Navert $\mathrm{H}$, et al. Hindgut dysgenesis as a cause of constipation with delayed colonic transit. Dig Dis Sci 1986; 31 993-9.

29 Stivland T, Camilleri M, Vassallo $M$, Proano $M$, Rath D, Brown $M$, et al. Scintigraphic measurement of regional gut transit in idiopathic constipation. Gastroenterology 1991; 101: $107-15$.

30 Vassallo M, Camilleri M, Phillips SF, Brown ML, Chapman NJ, Thomforde GM. Transit through the proximal colon influences stool weight in the irritable bowel syndrome. Gastroenterology 1992; 102: 102-8. 